\title{
Particle Receiver Integrated with Fluidized Bed
}

\section{NATIONAL RENEWABLE ENERGY LABORATORY}

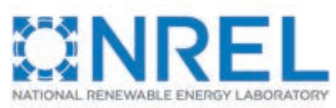

$\begin{array}{ll}\text { PROGRAM: } & \text { SunShot CSP R\&D } 2012 \\ \text { TOPIC: } & \text { Advanced Receivers }\end{array}$

LOCATION: Golden, Colorado

AWARD

AMOUNT:

Up to $\$ 3.8$ million

PROJECT TERM: $\quad 2012-2015$

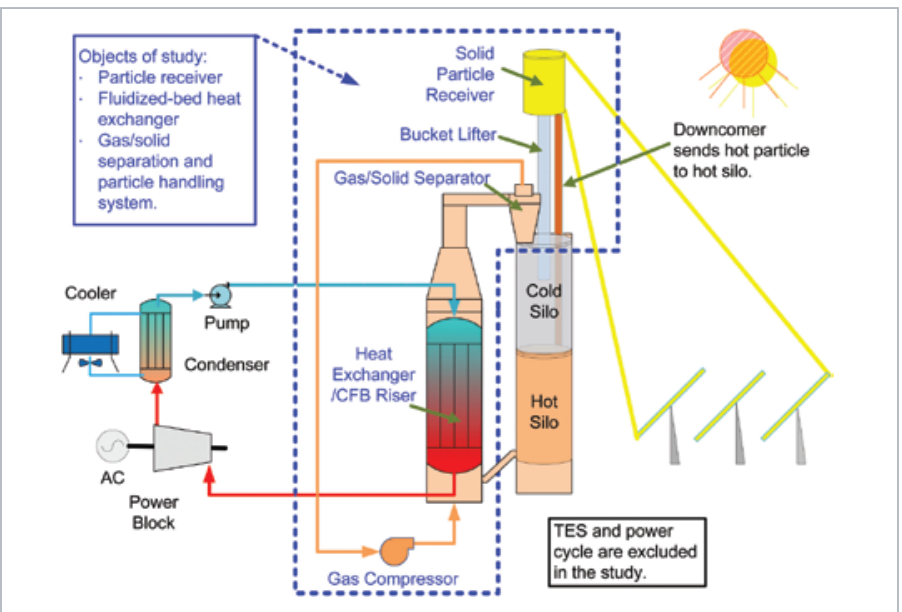

Schematic of fluidized-bed CSP system with solid-particle receiver and thermal energy storage. Illustration from NREL

\section{MOTIVATION}

The current state-of-the-art, nitrate-based molten-salt systems have limited potential for cost reduction and improvements in performance. Even with significant improvements, these systems face major challenges to satisfy the SunShot performance targets for a concentrating solar power (CSP) plant, which include high-temperature stability $\left(>650^{\circ} \mathrm{C}\right)$, low freezing point $\left(<0^{\circ} \mathrm{C}\right)$, and material compatibility with high-temperature metals $\left(>650^{\circ} \mathrm{C}\right)$ at a reduced cost.

\section{PROJECT DESCRIPTION}

The research team is working to develop a technology that uses gas/solid, two-phase flow as a heat-transfer fluid and separated, stable, solid particles as a thermal energy storage medium. The team is developing a near-blackbody particle receiver and an integrated fluidized-bed heat exchanger with auxiliary components to drive high-efficiency power cycles and achieve greater than $20 \%$ cost reduction over current CSP plants.

\section{IMPACT}

This project provides a pathway for CSP plants to increase their solar-to-electric conversion efficiency and reduce costs in the areas of solar collection from the solar field to the receiver, energy conversion systems, and thermal energy storage.

\section{CONTACTS}

Project Leader:

Dr. Zhiwen Ma

Zhiwen.Ma@nrel.gov
Partnering Organizations:

- Babcock \& Wilcox Power Generation Group, Inc.

- Massachusetts Institute of Technology

For more information, visit the project page at: www.solar.energy.gov/sunshot/csp_sunshotrnd_nrel_receiver.html. 